\title{
Introduction to the multi-author review on macular degeneration
}

\author{
Anu Kauppinen ${ }^{1} \mathbb{D}$
}

Received: 4 December 2019 / Revised: 4 December 2019 / Accepted: 10 December 2019 / Published online: 2 January 2020

(c) The Author(s) 2020

\begin{abstract}
Prolonged life expectancies contribute to the increasing prevalence of age-related macular degeneration (AMD) that is already the leading cause of severe vision loss among the elderly in developed countries. In dry AMD, the disease culminates into vast retinal atrophy, whereas the wet form is characterized by retinal edema and sudden vision loss due to neovascularization originating from the choroid beneath the Bruch's membrane. There is no treatment for dry AMD and despite intravitreal injections of anti-vascular endothelial growth factor (VEGF) that suppress the neovessel formation, also wet AMD needs new therapies to prevent the disease progression and to serve patients lacking of positive response to current medicines. Knowledge on disease mechanisms is a prerequisite for the drug development, which is hindered by the multifactorial nature of AMD. Numerous distinguished publications have revealed AMD mechanisms at the cellular and molecular level and in this multi-author review, we take a bit broader look at the topic with some novel aspects.
\end{abstract}

Keywords Age-related macular degeneration $\cdot$ Senescence $\cdot$ Immune cells $\cdot$ Epigenetics $\cdot$ Hypoxia $\cdot$ Lipocalin

Age-related macular degeneration (AMD) is an ocular disease localizing mainly at the macular area, which is responsible for central and sharp vision at the posterior part of the eye. The disease impairs, e.g. abilities to read, dial numbers, recognize faces and thereby, it severely compromises independency in daily tasks [3]. Loss of photoreceptors is preceded by the dysfunctionality and death of retinal pigment epithelium (RPE) cells that normally form a solid single-cell layer between photoreceptors and the Bruch's membrane. Reasons for the RPE degeneration are diverse but immune dysfunction, oxidative stress, mitochondrial damage, disturbed proteostasis, complement activation, and inflammation constantly recur in publications $[1,3,6,8-12,16,19]$. Despite the central role of the RPE, cells of innate and adaptive immunity are also involved in the pathogenesis of AMD. Chemokines secreted upon retinal damage recruit resident microglia as well as systemic leukocytes to the subretinal area [3]. Here, Verena Behnke et al. provide insight into the role of immune cells in AMD.

In a systematic meta-analysis with 16 identified risk factors, aging, current smoking, cataract surgery, and a family

Anu Kauppinen

anu.kauppinen@uef.fi

1 Faculty of Health Sciences, School of Pharmacy, University of Eastern Finland, 1627, 70211 Kuopio, Finland history were strongly associated with late AMD that can be divided into dry and wet forms $[4,5]$. Also, cardiovascular disease-related factors, such as hypertension, and a history with cardiovascular disease were observed as significant risk factors for AMD [5]. Aging is a strong prerequisite for AMD, the prevalence of which is low in people under 60 years [20]. Aging is associated with cellular senescence [7] that is contemplated in this multi-author review (MAR) by Janusz Błasiak in relation to premises of RPE cells upon stressful conditions.

In addition to environmental risk factors, genetic predisposition is associated with AMD and especially immune modulation and complement system are represented among susceptibility genes [15]. It has been observed that the role of genetic factors ranges from 46 to $71 \%$ in AMD [17, 20]. Nowadays, it is known that in addition to inherited genes, epigenetic modulation can change gene activity and expression without altering the DNA sequence [21]. Contribution of epigenetics is a very current topic in which interest also in relation to AMD is increasing, and that subject is covered here by Maria Gemenetzi and Andrew Lotery.

Intracellular accumulation of lipofuscin in lysosomes and extracellular drusen deposits between the RPE and the Bruch's membrane are the first clinical signs observed upon diagnosis of AMD [14]. Drusen and retinal edema are included in factors resulting in hypoxia found in AMD 
eyes [18]. The role of hypoxia in ocular neovascularization has recently been reviewed elsewhere [2] and in this MAR, hypoxia is considered from the perspective of gene therapy by Parviz Mammadzada et al.

Lipocalin-2 (LCN-2) belongs to the lipocalin protein family, the members of which share evolutionarily conserved eight-stranded antiparallel $\beta$-sheet "barrel" structure with capacity to bind small hydrophobic ligands [13]. LCN-2 is associated with infections, acute inflammation, as well as several chronic diseases [13]. Its role in AMD has not gained much attention but is now being compiled by Sayan Ghosh et al.

RPE cells are in the central role in the pathogenesis of AMD but several important players beyond them must also be taken into account when considering this multifactorial disease. This multi-author review presents AMD from other perspectives deepening the understanding on its pathogenesis and providing views for new therapy options.

Acknowledgements Open access funding provided by University of Eastern Finland (UEF) including Kuopio University Hospital.

Open Access This article is licensed under a Creative Commons Attribution 4.0 International License, which permits use, sharing, adaptation, distribution and reproduction in any medium or format, as long as you give appropriate credit to the original author(s) and the source, provide a link to the Creative Commons licence, and indicate if changes were made. The images or other third party material in this article are included in the article's Creative Commons licence, unless indicated otherwise in a credit line to the material. If material is not included in the article's Creative Commons licence and your intended use is not permitted by statutory regulation or exceeds the permitted use, you will need to obtain permission directly from the copyright holder. To view a copy of this licence, visit http://creativecommons.org/licenses/by/4.0/.

\section{References}

1. Akhtar-Schafer I, Wang L, Krohne TU, Xu H, Langmann T (2018) Modulation of three key innate immune pathways for the most common retinal degenerative diseases. EMBO Mol Med. https:// doi.org/10.15252/emmm.201708259

2. Alizadeh E, Mammadzada P, Andre H (2018) The different facades of retinal and choroidal endothelial cells in response to hypoxia. Int J Mol Sci. https://doi.org/10.3390/ijms19123846

3. Ambati J, Atkinson JP, Gelfand BD (2013) Immunology of agerelated macular degeneration. Nat Rev Immunol 13:438-451

4. Ardeljan D, Chan CC (2013) Aging is not a disease: distinguishing age-related macular degeneration from aging. Prog Retin Eye Res 37:68-69
5. Chakravarthy U, Wong TY, Fletcher A, Piault E, Evans C, Zlateva G, Buggage R, Pleil A, Mitchell P (2010) Clinical risk factors for age-related macular degeneration: a systematic review and metaanalysis. BMC Ophthalmol 10:31

6. Chen M, Luo C, Zhao J, Devarajan G, Xu H (2019) Immune regulation in the aging retina. Prog Retin Eye Res 69:159-172

7. Childs BG, Durik M, Baker DJ, van Deursen JM (2015) Cellular senescence in aging and age-related disease: from mechanisms to therapy. Nat Med 21:1424-1435

8. Copland DA, Theodoropoulou S, Liu J, Dick AD (2018) A perspective of AMD through the eyes of immunology. Investig Ophthalmol Vis Sci 59:AMD83-AMD92

9. Ferrington DA, Sinha D, Kaarniranta K (2016) Defects in retinal pigment epithelial cell proteolysis and the pathology associated with age-related macular degeneration. Prog Retin Eye Res 51:69-89

10. Kauppinen A, Paterno JJ, Blasiak J, Salminen A, Kaarniranta K (2016) Inflammation and its role in age-related macular degeneration. Cell Mol Life Sci 73:1765-1786

11. Kauppinen A (2017) Mitochondria-associated inflammasome activation and its impact on aging and age-related diseases. In: Fulop T, Franceschi C, Hirokawa K, Pawelec G (eds) Handbook of immunosenescence: basic understanding and clinical implications. Springer International Publishing, Cham, pp 1-20

12. Lefevere E, Toft-Kehler AK, Vohra R, Kolko M, Moons L, Van Hove I (2017) Mitochondrial dysfunction underlying outer retinal diseases. Mitochondrion 36:66-76

13. Li D, Yan Sun W, Fu B, Xu A, Wang Y (2019) Lipocalin-2-the myth of its expression and function. Basic Clin Pharmacol Toxicol. https://doi.org/10.1111/bcpt.13332

14. Lim LS, Mitchell P, Seddon JM, Holz FG, Wong TY (2012) Agerelated macular degeneration. Lancet 379:1728-1738

15. Mousavi M, Armstrong RA (2013) Genetic risk factors and agerelated macular degeneration (AMD). J Optom 6:176-184

16. Salminen A, Ojala J, Kaarniranta K, Kauppinen A (2012) Mitochondrial dysfunction and oxidative stress activate inflammasomes: impact on the aging process and age-related diseases. Cell Mol Life Sci 69:2999-3013

17. Seddon JM, Ajani UA, Mitchell BD (1997) Familial aggregation of age-related maculopathy. Am J Ophthalmol 123:199-206

18. Stefansson E, Geirsdottir A, Sigurdsson H (2011) Metabolic physiology in age related macular degeneration. Prog Retin Eye Res 30:72-80

19. Sugita S, Horie S, Yamada Y, Mochizuki M (2010) Inhibition of B-cell activation by retinal pigment epithelium. Investig Ophthalmol Vis Sci 51:5783-5788

20. Warwick A, Lotery A (2018) Genetics and genetic testing for age-related macular degeneration. Eye (Lond) 32:849-857

21. Weinhold B (2006) Epigenetics: the science of change. Environ Health Perspect 114:A160-A167

Publisher's Note Springer Nature remains neutral with regard to jurisdictional claims in published maps and institutional affiliations. 